\title{
Photophysical, Photochemical, and BQ Quenching Properties of Zinc Phthalocyanines with Fused or Interrupted Extended Conjugation
}

\author{
Gülş̧ah Gümrülkçü, ${ }^{1}$ Gülnur Keser Karaoğlan, ${ }^{1}$ Ali Erdoğmuş, ${ }^{1}$ \\ Ahmet Gül, ${ }^{2}$ and Ulvi Avcıata ${ }^{1}$ \\ ${ }^{1}$ Department of Chemistry, Technical University of Yildiz, Davutpasa, 34220 Istanbul, Turkey \\ ${ }^{2}$ Department of Chemistry, Technical University of Istanbul, Maslak, 34469 Istanbul, Turkey \\ Correspondence should be addressed to Gülşah Gümrükçü; gumrukcugulsah@hotmail.com \\ and Gülnur Keser Karaoğlan; gulnurkeser@hotmail.com
}

Received 4 October 2013; Accepted 20 November 2013; Published 29 January 2014

Academic Editor: Kushal Qanungo

\begin{abstract}
Copyright ( 2014 Gülşah Gümrükçü et al. This is an open access article distributed under the Creative Commons Attribution License, which permits unrestricted use, distribution, and reproduction in any medium, provided the original work is properly cited.

The effects of substituents and solvents on the photophysical and photochemical parameters of zinc(II) phthalocyanines containing four Schiff's base substituents attached directly and through phenyleneoxy-bridges on peripheral positions are reported. The group effects on peripheral position and the continual and intermittent conjugation of the phthalocyanine molecules on the photophysical and photochemical properties are also investigated. General trends are described for photodegradation, singlet oxygen, and fluorescence quantum yields of these compounds in dimethylsulfoxide (DMSO), dimethylformamide (DMF), and tetrahydrofurane (THF). Among the different substituents, phthalocyanines with cinnamaldimine moieties (1c and 2c) have the highest singlet oxygen quantum yields $\left(\Phi_{\Delta}\right)$ and those with nitro groups (1a and 2a) have the highest fluorescence quantum yields in all the solvents used. The fluorescence of the substituted zinc(II) phthalocyanine complexes is effectively quenched by 1,4-benzoquinone (BQ) in these solvents.
\end{abstract}

\section{Introduction}

Phthalocyanines (Pcs) are remarkable macrocyclic compounds having magnificent physical and chemical properties [1]. Metallophthalocyanines (MPc) have been investigated in detail for many years due to their high chemical and thermal stability, high degree of aromaticity, and synthetic flexibility $[2,3]$. They have also found different applications in many fields ranging from industrial [4], technological $[5,6]$ to medical $[7,8]$. Metallophthalocyanine (MPc) derivatives are photoactive and may be employed in photosensitization when the central metal ion is diamagnetic or a nontransition metal element $[9,10]$. In this case, it is worth emphasizing the Pcs' application as photosensitizers in the photodynamic therapy (PDT) of tumours. MPcs could lead them to be more efficient sensitizers owing to their high triplet state quantum yields and long triplet lifetimes. The photophysical properties of the Pc dyes are based on the presence and nature of the central metal ion. MPcs with paramagnetic metal centers produce low cytotoxic singlet oxygen. Closed shell and diamagnetic ions, like $\mathrm{Zn}^{2+}, \mathrm{Ga}^{3+}$ and $\mathrm{Si}^{4+}$, play important role in Pc complexes and bring excellent properties such as high singlet oxygen generation which is very important for PDT efficiency of photosensitizes [11-13]. ZnPcs have been widely studied because of closed shell $\mathrm{d}^{10}$ configuration of the central $\mathrm{Zn}^{2+}$ ion; they cause optical spectra that are not complicated by additional bands, as in partially filled transition-metal Pc complexes. Having intensive absorption in the low energy side (red) of visible region, high triplet yields, and efficient singlet oxygen generation makes ZnPcs valuable photosensitizers for PDT applications [14-17]. The general synthesis of organic solvent soluble substituted phthalocyanines is now well established. Pc complexes containing S, N, or O containing substituents 
are known [18-20]. However the study of the photochemical and photophysical properties of such complexes is still very limited.

We have recently reported on the synthesis, characterization, and photophysical and photochemical properties of [2,9,16,23-tetra-(salicylaldimino)phthtalocyaninatozinc(II)] and $[2,9,16,23$-Tetra-\{8-hydroxyquinolinato-salicydenaminatozinc(II)\}phthtalocyaninato-zinc(II)] [21]. In this work the photophysical and photochemical properties of tetrasubstituted zinc-phthalocyanines with unsaturated cinnamaldimine moieties attached to the inner core through phenoxy-bridges [22] and a new water-soluble tetracationic zinc phthalocyanine [23] which contains four conjugated Schiff's base groups at the peripheral positions are reported. The effect of the tetrasubstitution of zinc Pcs on their photophysical and photochemical properties will be evaluated in dimethylsulfoxide (DMSO), dimethylformamide (DMF), and tetrahydrofurane (THF).

\section{Experimental}

2.1. Materials. Dimethylsulphoxide (DMSO), tetrahydrofuran (THF), and dimethylformamide (DMF) were dried before use as described in Perrin and Armarego [24]. Unsubstituted zinc phthalocyanine, 1, 3-diphenylisobenzofuran $(\mathrm{DPBF})$, and 1,4-benzoquinone (BQ) were purchased from Sigma Aldrich. [2, 9, 16, 23-Tetra-(4-[4-nitrophenoxy])-phthtalocyaninatozinc(II)] (1a) [22], [2,9,16,23-tetra(4-[4-aminophenoxy])-phthtalocyaninatozinc(II)] (1b) [22], $[2,9,16,23-$ tetra-(4-[4-(\{(1Z,2E)-3-[4-(dimethylamino)phenyl]prop-2-en-1-ylideneimino)phenoxy])-phthtalocyaninatozinc(II)] (1c) [22], tetrakis-([4-(trimethylamino) phenyl]prop-2-en-1-ylideneimino)phenoxy])-phthtalocyaninatozinc(II))tetra-iodide (1d) [22], [2(3),9(10),16(17),23(24)tetra-nitro-phthtalocyaninatozinc(II)] (2a) [23], [2(3),9(10), 16(17),23(24)-tetraaminophthtalocyaninato zinc(II)] (2b) [23], [2,9,16,23-tetra-(4-[(1E)-3-iminoprop-1-en-1-yl]phenyl\} dimethylamino)phthtalocyaninatozinc(II)] (2c) [23], and tetrakis-(4-[(1E)-3-iminoprop-1-en-1-yl]-N,N,N-trimethylphenylammonium)phthalocyaninato zinc(II)] tetraiodide (2d) [23] were synthesized and purified according to the literature procedures.

2.2. Equipment. Absorption spectra in the UV-visible region were recorded with a Shimadzu 2001 UV spectrophotometer. Fluorescence excitation and emission spectra were recorded on a Varian Eclipse spectrofluorometer using $1 \mathrm{~cm}$ path length cuvettes at room temperature. Photoirradiations were done using a General Electric quartz line lamp $(300 \mathrm{~W})$. A $600 \mathrm{~nm}$ glass cut-off filter (Schott) and a water filter were used to filter off ultraviolet and infrared radiations, respectively. An interference filter (Intor, $670 \mathrm{~nm}$ with a band width of $40 \mathrm{~nm}$ ) was additionally placed in the light path before the sample. Light intensities were measured with a POWER MAX5100 (Molectron detector incorporated) power meter.

\subsection{Photophysical Parameters}

2.3.1. Fluorescence Quantum Yields. Fluorescence quantum yields $\left(\Phi_{F}\right)$ were determined by the comparative method (1) $[29,30]$, as follows:

$$
\Phi_{F}=\Phi_{F(\mathrm{Std})} \frac{F \cdot A_{\mathrm{Std}} \cdot n^{2}}{F_{\mathrm{Std}} \cdot A \cdot n_{\mathrm{Std}}^{2}},
$$

where $F$ and $F_{\text {Std }}$ are the areas under the fluorescence emission curves of the samples (1a-1d and $\mathbf{2 a - 2 d}$ ) and the standard, respectively. $A$ and $A_{\text {Std }}$ are the respective absorbances of the samples and standard at the excitation wavelengths, respectively. $n$ and $n_{\text {Std }}$ are the refractive indices of solvents used for the sample and standard, respectively. Unsubstituted ZnPc (in DMSO) $\left(\Phi_{F}=0.20\right)$ [28] was employed as the standard. The absorbance of the solutions at the excitation wavelength ranged between 0.04 and 0.05 .

2.3.2. Fluorescence Quenching by Benzoquinone (BQ). Fluorescence quenching experiments on the substituted zinc phthalocyanine derivatives (1a-1d and $\mathbf{2 a - 2 d}$ ) were carried out by the addition of different concentrations of $B Q$ to a fixed concentration of the complexes, and the concentrations of $\mathrm{BQ}$ in the resulting mixtures were $0,0.008,0.016,0.024,0.032$, and $0.040 \mathrm{~mol} \mathrm{dm}^{-3}$. The fluorescence spectra of substituted zinc phthalocyanine derivatives (1a-1d and $\mathbf{2 a - 2 d}$ ) at each $\mathrm{BQ}$ concentration were recorded, and the changes in fluorescence intensity related to BQ concentration by the SternVolmer (S-V) equation [31] were shown in (2):

$$
\frac{I_{0}}{I}=1+K_{\mathrm{SV}}[\mathrm{BQ}]
$$

where $I_{0}$ and $I$ are the fluorescence intensities of fluorophore in the absence and presence of quencher, respectively. The ratios of $I_{0} / I$ were calculated and plotted against [BQ] according to (2), and $K_{\mathrm{SV}}$ is determined from the slope.

\subsection{Photochemical Parameters}

2.4.1. Singlet Oxygen Quantum Yields. Singlet oxygen quantum yield $\left(\Phi_{\Delta}\right)$ determinations were carried out using the experimental setup described in the literature [32-34]. Typically, a $3 \mathrm{~mL}$ portion of the phthalocyanine derivatives, (absorbance $\sim 1$ at the irradiation wavelength) containing the singlet oxygen quencher, was irradiated in the $\mathrm{Q}$ band region with the photo-irradiation setup described in references [32$34]$. Singlet oxygen quantum yields $\left(\Phi_{\Delta}\right)$ were determined in air using the relative method with $\mathrm{ZnPc}$ (in DMSO, DMF, and THF) as a reference. DPBF was used as chemical quencher for singlet oxygen in DMSO, DMF, and THF. Equation (3) was employed for the following calculations:

$$
\Phi_{\Delta}=\Phi_{\Delta}^{\mathrm{Std}} \frac{R \cdot I_{\mathrm{abs}}^{\mathrm{Std}}}{R^{\mathrm{Std}} \cdot I_{\mathrm{abs}}},
$$

where $\Phi_{\Delta}^{\text {Std }}$ is the singlet oxygen quantum yields for the standard unsubstituted $\mathrm{ZnPc}\left(\Phi_{\Delta}^{\text {Std }}=0.67\right.$ in DMSO [35], 
$\Phi_{\Delta}^{\mathrm{Std}}=0.56$ in DMF [36], and $\Phi_{\Delta}^{\mathrm{Std}}=0.53$ in THF [27]). $R$ and $R_{\text {Std }}$ are the DPBF photobleaching rates in the presence of the respective samples (1a-1d and $\mathbf{2 a - 2 d )}$ and standard, respectively. $I_{\mathrm{abs}}$ and $I_{\mathrm{abs}}^{\text {Std }}$ are the rates of light absorption by the samples (1a-1d and 2a-2d) and standard, respectively. To avoid chain reactions induced by DPBF in the presence of singlet oxygen [36], the concentration of quencher (DPBF) was lowered to $\sim 3.10^{-5} \mathrm{M}$. Solutions of sensitizer $(C=1 \times$ $10^{-5} \mathrm{M}$ ) containing DPBF were prepared in the dark and irradiated in the $\mathrm{Q}$ band region using the photo-irradiation setup. DPBF degradation at $417 \mathrm{~nm}$ was monitored. The light intensity $6.75 \times 10^{15}$ photons s ${ }^{-1} \cdot \mathrm{cm}^{-2}$ was used for $\Phi_{\Delta}$ determinations.

2.4.2. Photodegradation Quantum Yields. Photodegradation quantum yield $\left(\Phi_{d}\right)$ determinations were carried out using the experimental setup described in the literature [32-34]. Photodegradation quantum yields were determined using (4), as follows:

$$
\Phi_{d}=\frac{\left(C_{0}-C_{t}\right) \cdot V \cdot N_{A}}{I_{\mathrm{abs}} \cdot S \cdot t}
$$

where $C_{0}$ and $C_{t}$ are the samples (1a-1d and 2a-2d) concentrations before and after irradiation, respectively, $V$ is the reaction volume, $N_{A}$ is the Avogadro's constant, $S$ is the irradiated cell area, $t$ is the irradiation time, and $I_{\text {abs }}$ is the overlap integral of the radiation source light intensity and the absorption of the samples (1a-1d and 2a-2d). A light intensity of $2.24 \times 10^{16}$ photons s ${ }^{-1} \mathrm{~cm}^{-2}$ was employed for $\Phi_{d}$ determinations.

\section{Results and Discussions}

3.1. Ground State Electronic Absorption and Fluorescence Spectra. The UV-Vis spectra of the phthalocyanine complexes exhibits characteristic Q- and B-bands. Two-principle $\pi-\pi^{*}$ transitions are seen for phthalocyanines: a Q-band $(\sim 700 \mathrm{~nm}$, a $\pi-\pi^{*}$ transition from the highest occupied molecular orbital (HOMO) to the lowest unoccupied molecular orbital (LUMO) of the complexes) and a B-band ( $2300-350 \mathrm{~nm}$, a deeper $\pi-\pi^{*}$ transition from the HOMO's $\left(\mathrm{a}_{1 \mathrm{u}}\right.$ and $\left.\mathrm{a}_{2 \mathrm{u}}\right)$ to the LUMO $\left.\left(e_{g}\right)\right)[37,38]$. The Q-band absorptions in the UV-Vis absorption spectra of the phthalocyanines (1a-1d and $\mathbf{2 b} \mathbf{b}-\mathbf{2 d}$ ) were observed as a single high intensity band due to a $\pi-\pi^{*}$ transition at around 677-686 and 685-720 nm in DMSO, 674-682 and 685-714 nm in DMF, and 672-679 [22] and 683$711 \mathrm{~nm}$ in THF, respectively, Table 1 and Figure 1. The other bands (B) in the UV region at $348-363$ and $349-363 \mathrm{~nm}$ in DMSO, 350-378 and 338-368 nm in DMF and 348-383 [22] and $349-357 \mathrm{~nm}$ in THF were observed due to the transitions from the deeper $\pi$ levels to the LUMO $[39,40]$.

Aggregation behavior of Pc is depicted as a coplanar association of rings progressing from monomer to dimer and higher order complexes and it is dependent on concentration, nature of solvent and substituents, metal ions, and temperature [41]. Aggregation is not desired in MPc complexes since aggregates are generally photoinactive. Aggregation is more

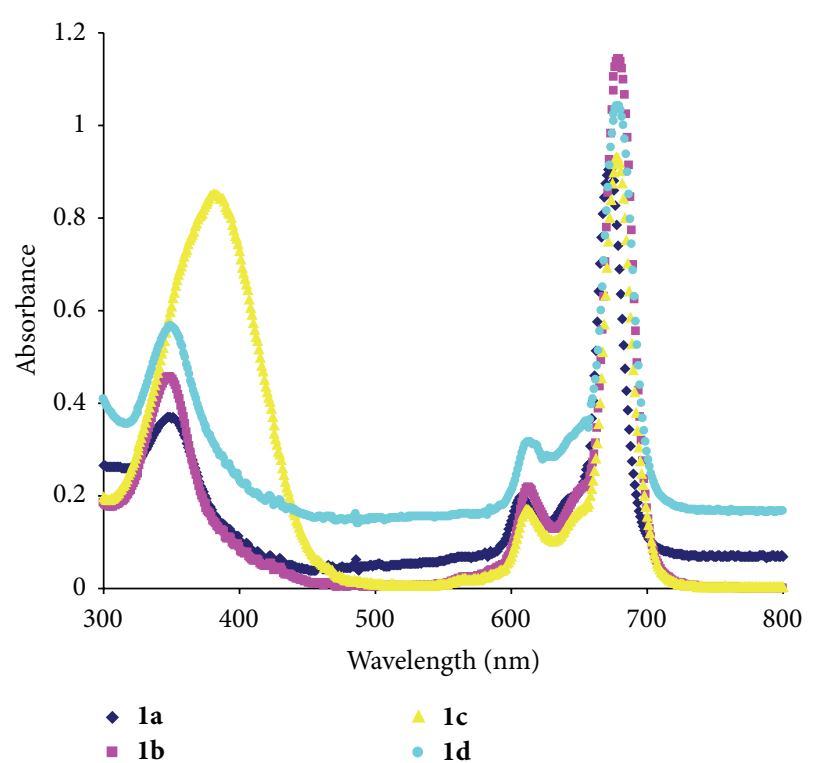

FIgURE 1: UV-Vis absorption spectra of complex la-1d in DMF.

enhanced for peripherally substituted MPc complexes when compared to nonperipherally substituted ones.

When aggregation occurs, a band in the region of 630$645 \mathrm{~nm}$ is observed in the electronic absorption spectrum of MPcs as a result of the intramolecular interactions between the Pc units. Thus, the band at around $640 \mathrm{~nm}$ in DMSO for 2a can be attributed to aggregation. Normally, DMSO is known to prevent aggregation since it is strong coordinating solvent. However, it has been observed before that aggregation occurs in DMSO for some MPc derivatives [42]. In the case of $\mathbf{2 a}$, where strong electron withdrawing nitro groups are placed as substituents, aggregation occurs in polar solvents. Depending on the polarity of the solvent, aggregated species are more dominant in DMSO, at appreciable level in DMF and hardly present in THF (Figure 2). In DMF, DMSO, and THF, the $\mathrm{Q}$ band positions of $\mathbf{1 b}$ are red-shifted relative to those of la with the same red-shifting being observed in all the solvents. The red shift as a consequence of the presence of amino groups on MPc spectra is well known $[22,23]$.

The flourescence behavior of the phthalocyanine complexes (1a-1d and 2a-2d) was studied in different solvents. Figure 2 shows fluorescence emission, absorption, and excitation spectra of complexes 1a and 2a in DMSO, DMF, and THF as examples of the studied zinc Pc complexes. Fluorescence emission and excitation peaks are listed in Table 1. The excitation spectra were similar to absorption spectra and both were mirror images of the fluorescent spectra for complexes 1a-1d. The shapes of the excitation spectra of studied compounds were similar to their absorption spectra. This proximity of the wavelength of the $\mathrm{Q}$ band absorption to the $\mathrm{Q}$ band maxima of the excitation spectrum for phthalocyanine compounds suggests that the nuclear configurations of the ground and excited states are similar and not affected by excitation in Figure 2 even though the absorption and fluorescence excitation spectra are not completely similar for $\mathbf{2 a - 2 d}$ due to conjugation effect of 
TABLE 1: Spectral parameters of $\mathbf{1 a - 1 d}$ and $\mathbf{2 a - 2 d}$ in DMSO, DMF, and THF.

\begin{tabular}{|c|c|c|c|c|c|}
\hline Solvent & Complex & $\begin{array}{c}\text { Q band } \\
\lambda_{\max },(\mathrm{nm})\end{array}$ & $\begin{array}{l}\text { Excitation } \\
\lambda_{\mathrm{Ex}},(\mathrm{nm})\end{array}$ & $\begin{array}{l}\text { Emission } \\
\lambda_{\mathrm{Em}},(\mathrm{nm})\end{array}$ & $\begin{array}{c}\text { Stokes shift } \\
\Delta_{\text {Stokes }},(\mathrm{nm}) \\
\end{array}$ \\
\hline DMSO & & 677 & 678 & 689 & 12 \\
\hline DMF & la & 674 & 676 & 686 & 12 \\
\hline THF & & $672^{\mathrm{a}}$ & 672 & 682 & 10 \\
\hline DMSO & & 685 & 689 & 697 & 12 \\
\hline DMF & $\mathbf{l b}$ & 682 & 683 & 693 & 11 \\
\hline THF & & $679^{\mathrm{a}}$ & 687 & 694 & 15 \\
\hline DMSO & & 686 & 690 & 696 & 10 \\
\hline DMF & 1c & 682 & 685 & 691 & 9 \\
\hline THF & & $678^{\mathrm{a}}$ & 681 & 686 & 8 \\
\hline DMSO & & 681 & 687 & 696 & 15 \\
\hline DMF & $1 d$ & 680 & 681 & 690 & 10 \\
\hline THF & & $679^{\mathrm{a}}$ & 681 & 690 & 11 \\
\hline DMSO & & 685 & 707 & 717 & 32 \\
\hline DMF & $2 a$ & 685 & 699 & 718 & 33 \\
\hline THF & & $683^{\mathrm{b}}$ & 690 & 702 & 19 \\
\hline DMSO & & 720 & 742 & 748 & 28 \\
\hline DMF & $2 b$ & 713 & 729 & 734 & 21 \\
\hline THF & & $708^{\mathrm{b}}$ & 713 & 710 & 2 \\
\hline DMSO & & 718 & 720 & 728 & 10 \\
\hline DMF & $2 c$ & 710 & 712 & 721 & 9 \\
\hline THF & & $705^{\mathrm{b}}$ & 705 & 712 & 7 \\
\hline DMSO & & $720^{\mathrm{b}}$ & 727 & 730 & 10 \\
\hline DMF & $2 d$ & $714^{\mathrm{b}}$ & 727 & 746 & 32 \\
\hline THF & & $711^{b}$ & 725 & 730 & 19 \\
\hline DMSO & $\mathrm{ZnPc}$ & $672^{c}$ & $672^{c}$ & $682^{c}$ & 10 \\
\hline DMF & $\mathrm{ZnPc}$ & $670^{\mathrm{d}}$ & $670^{\mathrm{d}}$ & $676^{\mathrm{d}}$ & 6 \\
\hline THF & $\mathrm{ZnPc}$ & $666^{\mathrm{e}}$ & $666^{\mathrm{e}}$ & $673^{e}$ & 7 \\
\hline
\end{tabular}

${ }^{a}$ Reference [21].

${ }^{\mathrm{b}}$ Reference [22].

${ }^{\mathrm{c}}$ Reference [25].

${ }^{\mathrm{d}}$ Reference [26].

${ }^{\mathrm{e}}$ Reference [27].

these groups and aggregation. It is evident from Figure 3 that the emission peaks of the two species (1a-1d and $\mathbf{2} \mathbf{a}-\mathbf{2} \mathbf{d})$ are shifted to longer wavelength as a result of conversion of $-\mathrm{NO}_{2}$ groups (1a and $\mathbf{2 a}$ ) into $-\mathrm{NH}_{2}$ on phenoxy groups ( $\mathbf{1 b}$ and 2b) in all solvents used. Spectral changes appearing as a result of enhanced conjugation have been clearly shown when the emission spectra of Pcs (2a-2d) are compared with those of analogous molecules (1a-1d) where identical substituents are attached not directly the Pc core but through phenylene-oxy bridges. As expected, emission bands of Pcs with conjugated cinnamaldimine groups show bathochromic shifts (Table 1). The observed Stokes shifts were within the region $(\sim 5-35 \mathrm{~nm})$ observed for zinc Pc complexes (1a-1d and 2a-2d).

\subsection{Photophysical Studies}

3.2.1. Fluorescence Quantum Yields. The fluorescence quantum yields $\left(\Phi_{F}\right)$ of zinc phthalocyanines (1a-1d and $\mathbf{2 a - 2 d}$ ) were studied in DMSO, DMF, and THF. Fluorescence is strongly influenced by factors such as solvent polarity, viscosity, refractive index, temperature, and molecular structural features. Fluorescence quantum yields $\left(\Phi_{F}\right)$ were calculated in all solvents as shown in Table 2.

While fluorescence quantum yield $\left(\Phi_{F}\right)$ values for 1a1d and 2a-2d in DMSO, DMF, and THF are lower than those for unsubstituted $\mathrm{ZnPc}\left(\Phi_{F}=0.20\right.$ in DMSO [28], $\Phi_{F}$ $=0.17$ in DMF [25], and $\Phi_{F}=0.25$ in THF [27], Table 2). This implies that the presence of the substituents (Scheme 1) caused low fluorescence of the parents $\mathrm{ZnPc}$ in DMSO, DMF, and THF. The continual conjugation of the substituents on the peripheral position of $\mathrm{ZnPc}$ increases electron density from Pc rings to substituents on peripheral position.

Higher $\Phi_{F}$ values were observed for the phthalocyanines including intermittent conjugation compared to the phthalocyanines including continual conjugation in DMSO, DMF, and THF except 1d and 2d in DMF and THF. Quaternized 
TABLE 2: Photophysical and photochemical properties of 1a-1d and 2a-2d in DMSO, DMF, and THF.

\begin{tabular}{|c|c|c|c|c|c|c|c|c|}
\hline Solvent & Complex & $\Phi_{F}$ & $\Phi_{\Delta}$ & $\Phi_{d}\left(\times 10^{-5}\right)$ & Complex & $\Phi_{F}$ & $\Phi_{\Delta}$ & $\Phi_{d}\left(\times 10^{-5}\right)$ \\
\hline DMSO & \multirow{3}{*}{ la } & 0.083 & 0.52 & 0.82 & \multirow{3}{*}{$2 a$} & 0.006 & 0.21 & 1.56 \\
\hline DMF & & 0.103 & 0.36 & 51.20 & & 0.035 & 0.35 & 20.36 \\
\hline THF & & 0.081 & 0.38 & 2.15 & & 0.053 & 0.18 & 5.43 \\
\hline DMSO & \multirow{3}{*}{ lb } & 0.027 & 0.20 & 2.42 & \multirow{3}{*}{$2 b$} & 0.005 & 0.10 & 30.06 \\
\hline DMF & & 0.011 & 0.12 & 42.15 & & 0.008 & 0.08 & 13.16 \\
\hline THF & & 0.047 & 0.16 & 5.21 & & 0.002 & 0.09 & 3.08 \\
\hline DMSO & \multirow{3}{*}{ lc } & 0.004 & 0.65 & 3.56 & \multirow{3}{*}{$2 c$} & 0.003 & 0.54 & 26.32 \\
\hline DMF & & 0.009 & 0.58 & 40.56 & & 0.007 & 0.51 & 31.42 \\
\hline THF & & 0.002 & 0.85 & 1.86 & & 0.009 & 0.62 & 3.88 \\
\hline DMSO & \multirow{3}{*}{ 1d } & 0.001 & 0.44 & 1.06 & \multirow{3}{*}{$2 d$} & 0.001 & 0.36 & 31.14 \\
\hline DMF & & 0.004 & 0.18 & 62.25 & & 0.026 & 0.11 & 52.32 \\
\hline THF & & 0.005 & 0.40 & 1.86 & & 0.017 & 0.30 & 6.78 \\
\hline DMSO & \multirow{3}{*}{ Std-ZnPc } & $0.20^{\mathrm{a}}$ & $0.67^{\mathrm{b}}$ & $0.26^{\mathrm{b}}$ & & & & \\
\hline DMF & & $0.17^{\mathrm{c}}$ & $0.56^{\mathrm{c}}$ & $0.023^{c}$ & & & & \\
\hline THF & & $0.25^{\mathrm{d}}$ & $0.53^{\mathrm{d}}$ & $0.002^{\mathrm{d}}$ & & & & \\
\hline
\end{tabular}

${ }^{a}$ Reference $[28]$.

${ }^{\mathrm{b}}$ Reference [25].

${ }^{\mathrm{c}}$ Reference [26].

${ }^{\mathrm{d}}$ Reference [27].

group 2d has higher $\Phi_{F}$ values than $\mathbf{1 d}$ partners due to showing less aggregation tendency. The zinc phthalocyanine complexes bearing nitro group (1a and $\mathbf{2 a}$ ) are more fluorescent than other studied phthalocyanine complexes in all solvents used due to the nature of the electron withdrawing nitro group. The zinc phthalocyanine complexes ( $\mathbf{l b}$ and 2b) showed that lowest emission could be as a result of converted $\mathrm{NO}_{2}$ group into $\mathrm{NH}_{2}$ on the Pc ring. Complexes 1a and 2a have higher fluorescence quantum yield $\left(\Phi_{F}\right)$ values than the other complexes and in DMSO, DMF, and THF due to electron withdrawing group effect. Fluorescence quantum yield $\left(\Phi_{F}\right)$ values of phthalocyanines substituted Schiff base groups on peripheral positions (1c and 2c) lowed when compared to $\mathbf{1 b}$ and $\mathbf{2} \mathbf{b}$ in DMSO and DMF $\mathbf{2 c}$ except in THF. This effect can be explained by electrondonating feature of Schiff groups. Fluorescence quantum yield $\left(\Phi_{F}\right)$ of quaternized phthalocyanines (1d and $\mathbf{2 d}$ ) has the lowest values than the other complexes. Quaternized group quenched fluorescence quantum yield due to group effects. Comparing $\Phi_{F}$ values of complexes among the three solvents, complex la has the highest fluorescence quantum yield $\Phi_{F}$ values in DMSO, DMF, and THF. Complexes $\mathbf{1 d}$ and $\mathbf{2 d}$ in DMSO, $\mathbf{1 d}$ in DMF, and $\mathbf{1 c}$ and $\mathbf{2 b}$ in THF (Table 2) have the lowest values, respectively. The trend was reversed in DMSO, DMF, and THF $\Phi_{F}$ values were obtained for the Pc derivatives.

\subsection{Photochemical Studies}

3.3.1. Singlet Oxygen Quantum Yields. Singlet oxygen quantum yield $\Phi_{\Delta}$ is a measure of singlet oxygen generation and the $\Phi_{\Delta}$ values were obtained using (3). Singlet oxygen quantum yields were studied in DMSO, DMF, and THF (for 1a-1d and 2a-2d) using a chemical method (using DPBF as a singlet oxygen quencher). Figure 4 shows spectral changes observed during photolysis of complexes $\mathbf{1 b}$ and $\mathbf{2} \mathbf{b}$ in THF in the presence of DPBF as an example. The disappearance of DPBF was monitored using UV-Vis spectral changes. There were no changes in the Q band intensities during the $\Phi_{\Delta}$ determinations, confirming that complexes are not degraded during singlet oxygen studies [43]. The complexes (1a-d and $\mathbf{2 a - d )}$ in this work were selected because they bore similar substituents; however they differed in their extended interrupted conjugation with phenoxy-bridges and continual conjugation bond linkages. We investigated the effect of this difference on the photophysicochemical properties. Phthalocyanines with fused extended conjugation (2a-2d) have lower singlet oxygen quantum yield when compared to phthalocyanines with interrupted extended conjugation (1a-1d) due to conjugation effect. Interrupted extended conjugation quenched singlet oxygen was generated. When the nature effect of groups on singlet oxygen quantum yields was investigated Schiff base groups (1c and $\mathbf{2 c}$ ) showed the highest values and quaternized groups (1d and $\mathbf{2} \mathbf{d}$ ) showed the lowest values in all solvents studied. The values of $\Phi_{\Delta}$ are higher for $\mathrm{ZnPc}$ complexes including intermittent conjugation when compared to $\mathrm{ZnPc}$ complexes including continual conjugation in all studied solvents. The $\Phi_{\Delta}$ values of complex 1c were higher than all the substituted complexes (1a-1d and 2a-2d) in DMSO, DMF and THF (Table 2). The values of $\Phi_{\Delta}$ for $1 c$ ( 0.58 in DMF, and 0.85 in THF) and for $2 \mathrm{c}(0.62$ in THF) are higher when compared to unsubstituted ZnPc in DMF (0.56 [26]) and THF (0.53 [44]), Table 2. The values of $\Phi_{\Delta}$ were the highest for $\mathbf{1 a - 1 d}$ in DMSO except 1c in THF. 


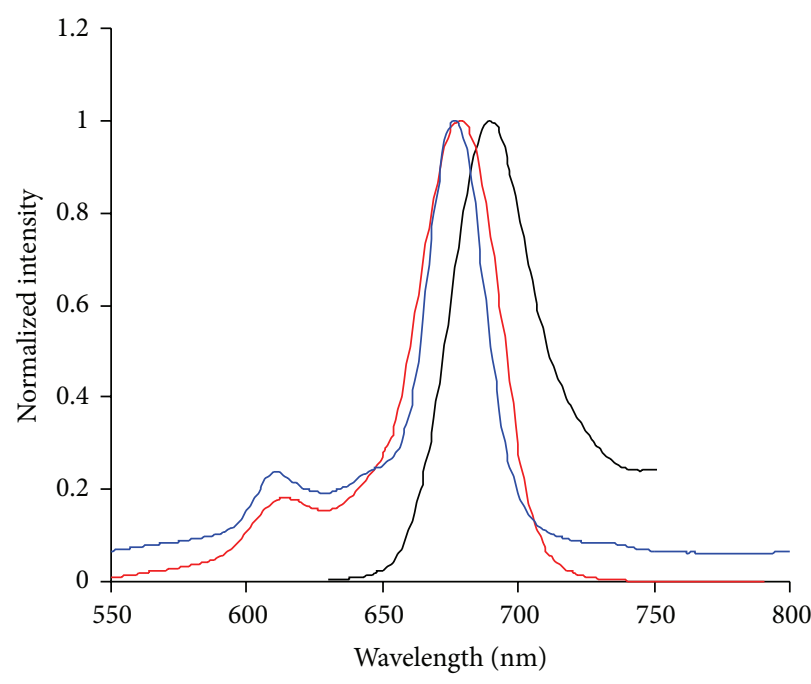

(a)

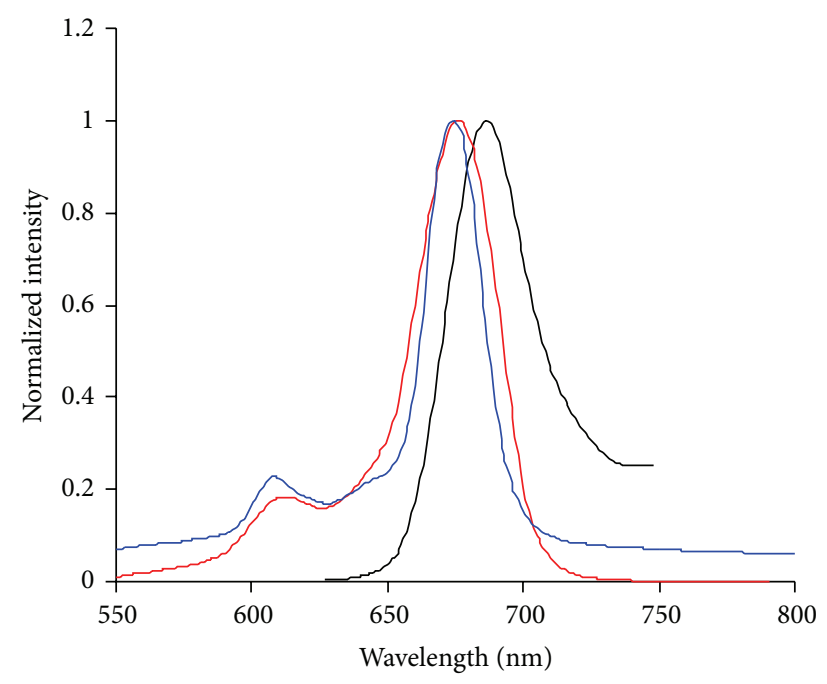

(b)

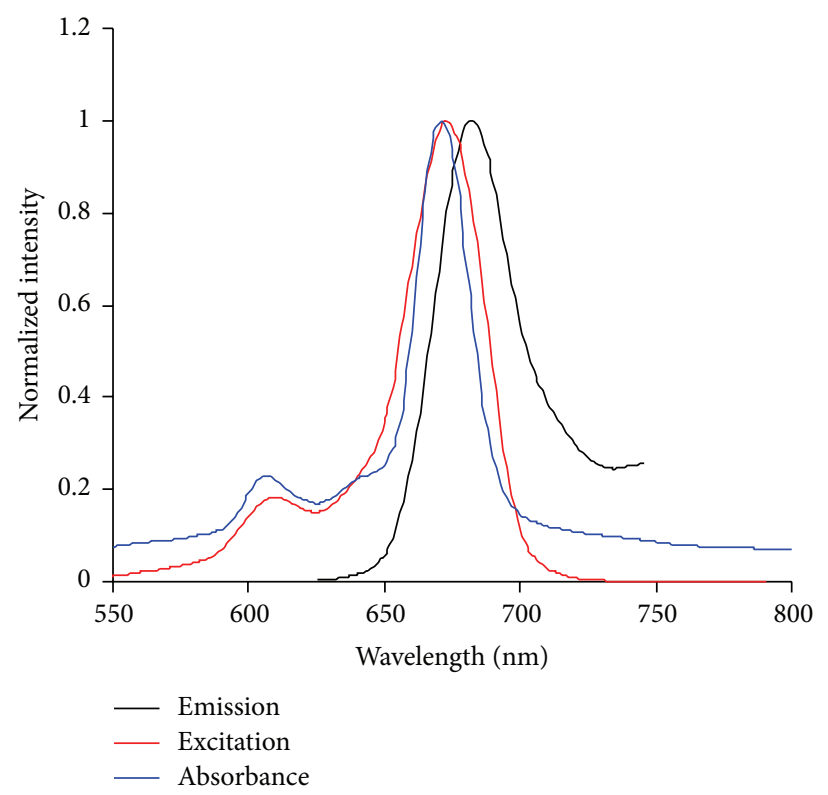

(c)

Figure 2: Absorption, excitation, and emission spectra for complex la in DMSO (a), DMF (b), and THF (c).

3.3.2. Photodegradation Studies. Photodegradation is a process where a phthalocyanine is degraded under light irradiation. It can be used to determinate MPcs stability and this is especially important for those molecules intended for use as photocatalysts. The photobleaching stabilities of studied zinc phthalocyanine complexes (1a-1d and $\mathbf{2 a - 2 d )}$ were determined in DMSO, DMF and THF by monitoring the decrease in the intensity of the $\mathrm{Q}$ band under irradiation with increasing time. The photodegradation quantum yield $\left(\Phi_{d}\right)$ values for the complexes are given in Table 2. All the complexes showed about the same stability with $\Phi_{d}$ of the order of $10^{-5}-10^{-4}$. These values show that the molecules are of moderate stability in all solvents used. Stable $\mathrm{ZnPc}$ molecules show values as low as $10^{-6}$ and for unstable molecules, values of the order $10^{-3}$ have been reported [45]. The spectral changes observed for all the complexes (1a-1d and 2a-2d) during irradiation confirmed that photodegradation occurred without phototransformation (Figure 5). $\Phi_{d}$ values of all complexes $\mathbf{1 a}-\mathbf{1 d}$ are higher in DMF than in DMSO and THF, corresponding to the low $\Phi_{\Delta}$ values in the former solvent, consistent with the notion that photodegradation is singlet oxygen mediated process. Complex la is more stable than complexes $\mathbf{1 b}-\mathbf{1 d}$ while complex $\mathbf{2} \mathbf{a}$ showed the highest stability in DMSO (Table 2). Photobleaching quantum yield values of complexes $\mathbf{2 a - 2 d}$ are lower than complexes 1a1d in both DMSO, DMF, and THF and hence complexes 2a-2d are more stable than complexes la-1d in the same solvents. In general photobleaching quantum yield values of phthalocyanines complexes are lower in DMSO than DMF. This trend was observed our complexes la-1d and 


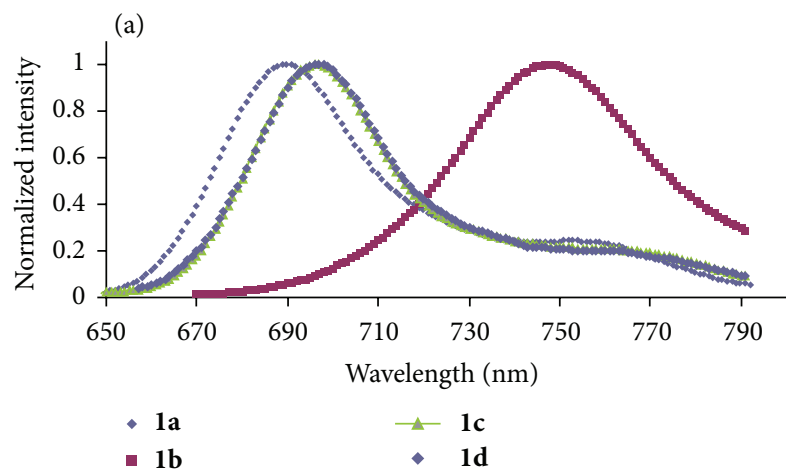

FIgURE 3: The emission peaks of the complexes (1a-1d) (a).

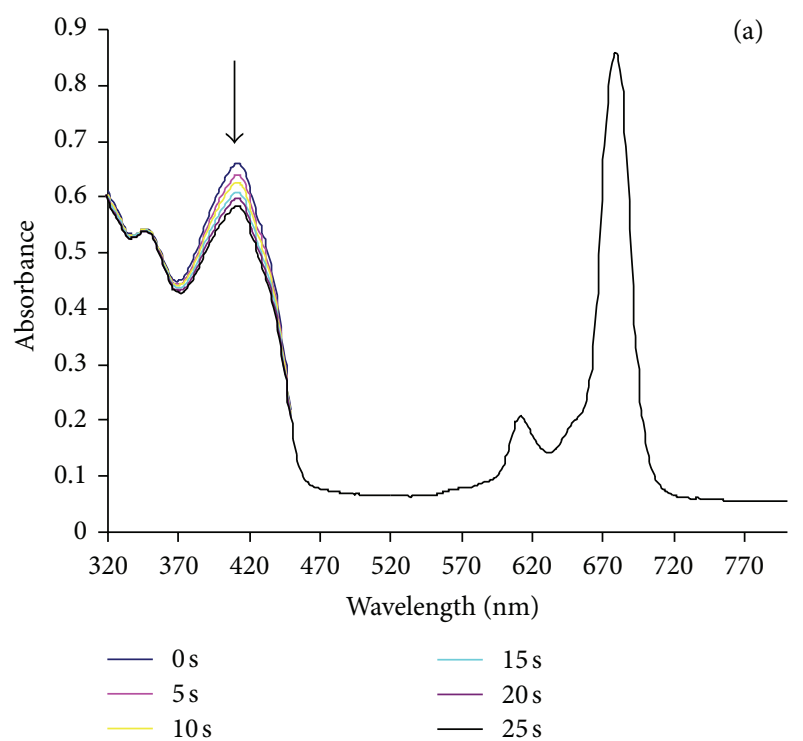

Figure 4: A typical spectrum for the determination of singlet oxygen quantum yield. This figure was for complex $\mathbf{l b}$ (a) in THF at a concentration of $6 \times 10^{-6} \mathrm{~mol} \mathrm{dm}^{-3}$.

$\mathbf{2 a}$, but other complexes $\mathbf{2 b - 2 d}$. These complexes showed unexpected trend $[46,47]$.

3.4. Fluorescence Quenching Studies by Benzoquinone. The fluorescence quenching of zinc phthalocyanine complexes (1a-1d and $\mathbf{2 a - 2 d}$ ) by benzoquinone (BQ) in DMSO, DMF, and THF was found to obey Stern-Volmer kinetics, which is consistent with diffusion-controlled bimolecular reactions. Figure 6 shows the quenching of complex $\mathbf{1 d}$ and $\mathbf{2 d}$ by BQ in DMSO as an example. The slope of the plots shown in Figure 7 gave $K_{\mathrm{SV}}$ values of $\mathbf{1 a - 1 d}$ in THF as an example, listed in Table 3. The Stern-Volmer plots for studied complexes (1a-1d and 2a-2d) gave straight lines, depicting diffusioncontrolled quenching mechanisms (Figure 7). Quinones have high electron affinities and their involvement in electron transfer processes is well documented [48]. The energy of the lowest excited state for quinones is greater than the energy of the excited singlet state of MPc complexes [49]; hence, energy transfer from the excited MPc to BQ is not likely

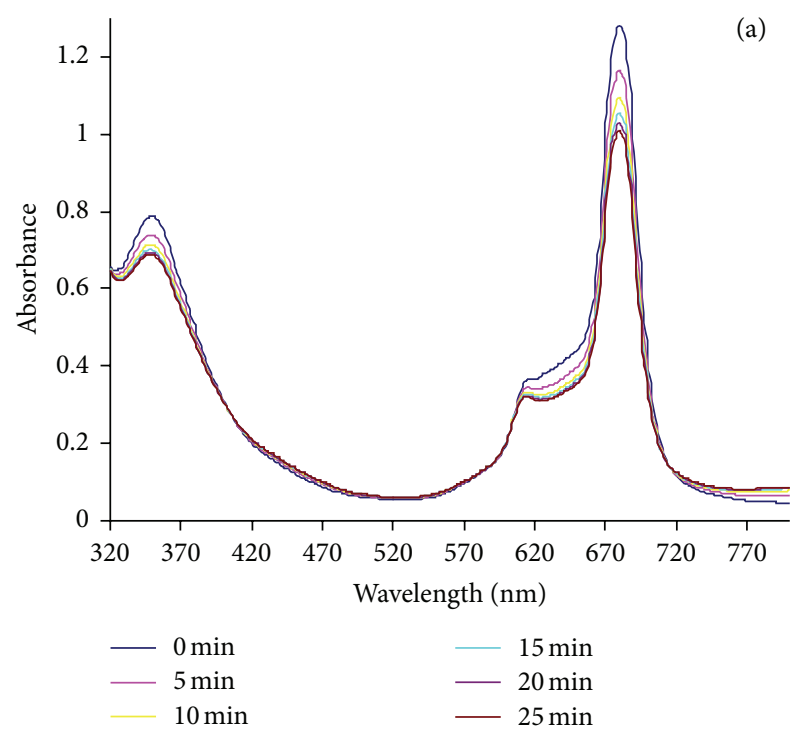

FIGURE 5: The photodegradation of compound 1d (a) in DMF showing the disappearance of the $\mathrm{Q}$ band at 5 min intervals.

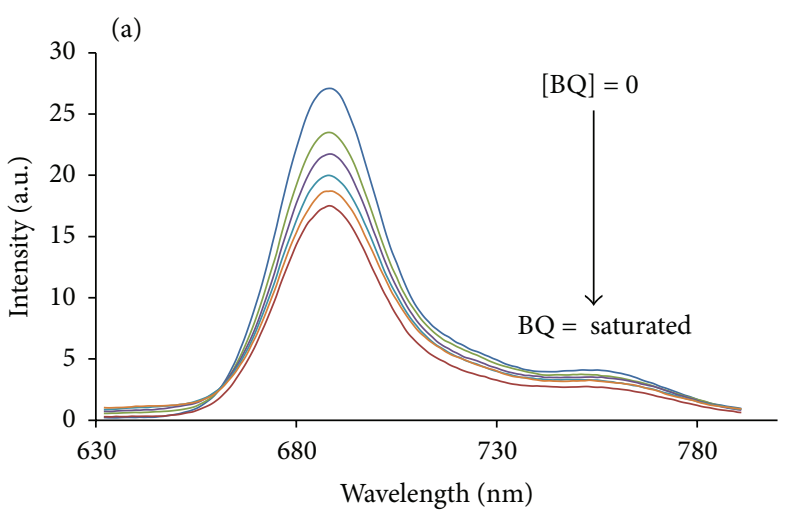

FIGURE 6: Fluorescence emission spectral changes of 1d (a) (1.00 $\times 10^{-5} \mathrm{~mol} \mathrm{dm}^{-3}$ ) on addition of different concentrations of $\mathrm{BQ}$ in THF. $[\mathrm{BQ}]=0,0.008,0.016,0.024,0.032$, and $0.040 \mathrm{~mol} \mathrm{dm}^{-3}$ and saturated with $\mathrm{BQ}$.

to occur. Moreover, MPcs are known to be easily reduced. Therefore MPc fluorescence quenching by BQ is via excited state electron transfer, from the MPc to the BQ [50]. The $K_{\mathrm{SV}}$ values for the BQ quenching of phthalocyanine complexes in different solvents are listed in Table 3 . The $K_{\mathrm{SV}}$ values of the substituted phthalocyanine complexes (1a-1d) are lower than Std-ZnPc in DMF and THF, while the values of the complexes (1a-1d) are similar to the Std-ZnPc approximately in DMSO. Generally, the $K_{\mathrm{SV}}$ values of the substituted phthalocyanine complexes (2a-2d) are similar to the Std-ZnPc approximately in DMSO while the $K_{\mathrm{SV}}$ values are lower in DMF and higher in THF than Std-ZnPc. When compared the substituted complexes (1a-1d and $\mathbf{2 a - 2 d}$ ), the substitution with Schiff base $\mathrm{Zn}$ (II) complex group including continual conjugation seems to increase the $K_{\mathrm{SV}}$ values of the complexes in DMF and THF. The orders of $K_{\mathrm{SV}}$ values for substituted complexes (1a-1d and $\mathbf{2 a - 2 d ) ~ a m o n g ~ t h e ~ s t u d i e d ~ s o l v e n t s ~ a r e ~ a s ~}$ follows: DMSO > DMF > THF except $1 \mathbf{d}$ in DMSO and 

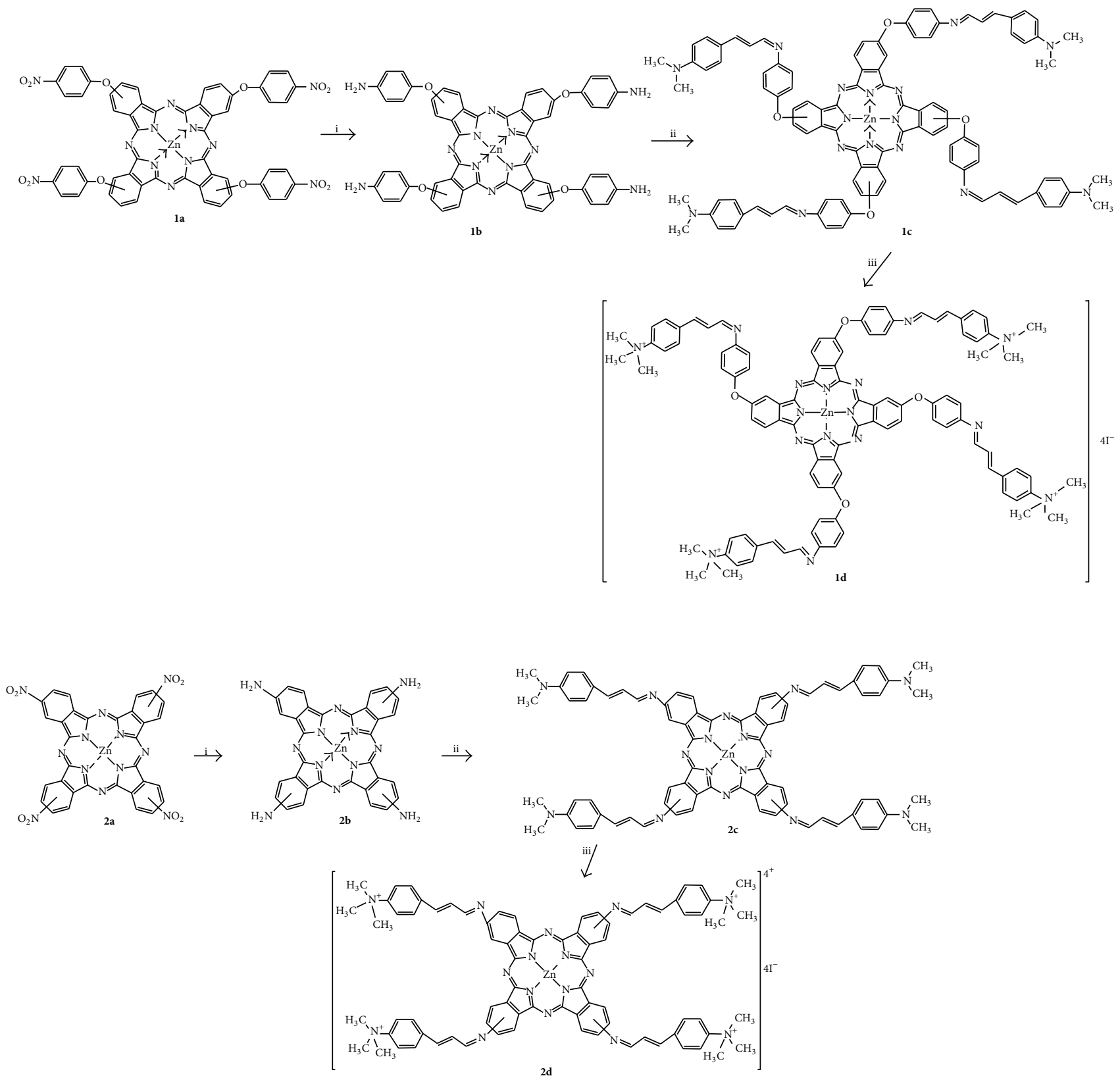

Scheme 1: Synthesis of zinc complexes. 1a-1d and 2a-2d ((i) Pd/C, hydrazine hydrate, dioxane, and reflux; (ii) 4-(dimethylamino) cinnamaldehyde, THF, and reflux; (iii) $\mathrm{CH}_{3} \mathrm{I}, \mathrm{CHCl}_{3}$, and reflux) $[22,23]$.

THF > DMF > DMSO except 2d in DMSO, respectively. In different solvents, the $K_{\mathrm{SV}}$ values for BQ quenching of phthalocyanine complexes vary directly with the solvents' polarity.

\section{Conclusion}

This work has described the spectral and photophysicochemical properties of $\mathrm{Zn}$ (II) phthalocyanines with fused or interrupted extended conjugation. The photophysical and photochemical properties of the phthalocyanines (1a-1d and $\mathbf{2 a -}$ 2d) were investigated in DMSO, DMF, and THF. The effect of the nature of substituent and solvents on the photophysical and photochemical parameters of the phthalocyanine complexes (1a-1d and $\mathbf{2 a - 2 d}$ ) are also reported in this study. The fluorescence quantum yields $\left(\Phi_{F}\right)$ values of complex la were higher than all the substituted complexes (1b-1d and $\mathbf{2 a -}$ 2d) in DMSO, DMF, and THF. The highest singlet oxygen quantum yield values were obtained for only $\mathbf{1 c}$ and $\mathbf{2 c}$ among the all complexes synthesized in DMF, DMSO, and THF. These properties give an indication of the potential of the complexes as photosensitizers in applications where singlet oxygen is required (type II mechanism), especially complexes $1 c$ and $2 c$ may be good candidate as a photosensitizer for PDT application. 
TABLE 3: Fluorescence quenching data of substituted zinc phthalocyanine complexes (1a-1d and $\mathbf{2 a - 2 d}$ ) in DMSO, DMF, and THF.

\begin{tabular}{lccc}
\hline Comp & DMSO & $\begin{array}{c}K_{\mathrm{SV}}\left(\mathrm{M}^{-1}\right) \\
\text { DMF }\end{array}$ & THF \\
\hline $\mathbf{1 a}$ & 33,07 & 23,96 & 19,79 \\
$\mathbf{1 b}$ & 44,64 & 24,36 & 9,21 \\
$\mathbf{1 c}$ & 32,54 & 31,82 & 30,21 \\
$\mathbf{1 d}$ & 22,43 & 30,32 & 11,57 \\
$\mathbf{2 a}$ & 31,61 & 42,43 & 77,04 \\
2b & 28,79 & 41,25 & 49,11 \\
2c & 33.65 & 48.03 & 63.28 \\
2d & 60,71 & 54,71 & 102,89 \\
ZnPc & $31.90^{\mathrm{a}}$ & $57.60^{\mathrm{b}}$ & $48.48^{\mathrm{c}}$ \\
\hline
\end{tabular}

${ }^{\mathrm{a}}$ Reference [25].

${ }^{\mathrm{b}}$ Reference [26].

${ }^{\mathrm{c}}$ Reference [27].

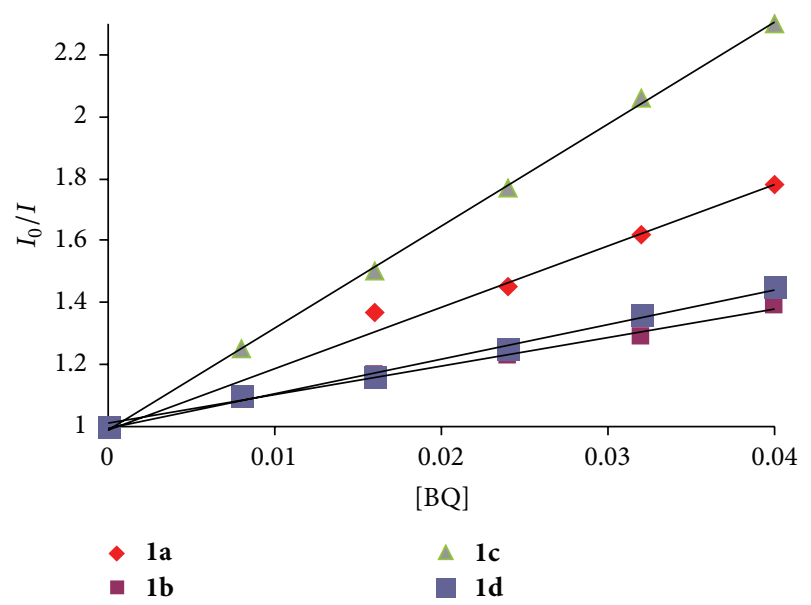

FIGURE 7: Stern-Volmer plots for benzoquinone (BQ) quenching of substituted zinc phthalocyanine complexes 1a-1d in THF. [MPc] $1.00 \times 10^{-5} \mathrm{~mol} \mathrm{dm}^{-3}$ in DMSO, DMF, and THF. [BQ] $=0,0.008$, $0.016,0.024,0.032$, and $0.040 \mathrm{~mol} \mathrm{dm}^{-3}$ in all solvents used.

\section{Conflict of Interests}

Gulsah Gumrukcu, Gulnur Keser Karaoglan, Ali Erdogmus, Ahmet Gül, and Ulvi Avcrata report no financial relationships to Merck or any companies.

\section{Acknowledgments}

This study was supported by Yildiz Technical University (Projects nos. 2012-01-02-KAP03 and 2012-01-02-GEP02). AG thanks Turkish Academy of Sciences (TUBA) for partial support.

\section{References}

[1] D. Dini and M. Hanack, "Physical properties of phthalocyaninebased materials," in The Porphyrin Handbook, K. M. Kadish, K. M. Smith, and R. Guilard, Eds., vol. 17, pp. 1-31, Elsevier Science, Boston, Mass, USA, 2003.
[2] N. B. McKeown, "The synthesis of symmetrical phthalocyanines," in The Porphyrin Handbook, K. M. Kadish, K. M. Smith, and R. Guilard, Eds., vol. 15, pp. 61-124, Academic Press, New York, NY, USA, 2003.

[3] C. C. Leznoff and A. B. P. Lever, Phthalocyanines: Properties and Applications, vol. 1-4, Wiley-VCH, Weinheim, Germany, 19891996.

[4] P. Gregory, "Industrial applications of phthalocyanines," Journal of Porphyrins and Phthalocyanines, vol. 4, pp. 432-437, 2000.

[5] K. Daimon, K. Nukada, Y. Sakaguchi, and R. Igarashi, "A new polymorph of hydroxygallium phthalocyanine and its application in a photoreceptor," Journal of Imaging Science and Technology, vol. 40, no. 3, pp. 249-253, 1996.

[6] A. Tracz, T. Makowski, S. Masirek, W. Pisula, and Y. H. Geerts, "Macroscopically aligned films of discotic phthalocyanine by zone casting," Nanotechnology, vol. 18, no. 48, Article ID 485303, 2007.

[7] S. A. Priola, A. Raines, and W. S. Caughey, "Porphyrin and phthalocyanine antiscrapie compounds," Science, vol. 287, no. 5457, pp. 1503-1506, 2000.

[8] E. Ben-Hur and W. S. Chan, "Phthalocyanines in photobiology and their medical applications," in The Porphyrin Handbook, K. Kadish, K. M. Smith, and R. Guilard, Eds., pp. 1-35, Academic Press, New York, NY, USA, 2003.

[9] E. Ben-Hur, M. Green, A. Prager, R. Kol, and I. Rosenthal, "Phthalocyanine photosensitization of mammalian cells: biochemical and ultrastructural effects," Photochemistry and Photobiology, vol. 46, no. 5, pp. 651-656, 1987.

[10] I. J. MacDonald and T. J. Dougherty, "Basic principles of photodynamic therapy," Journal of Porphyrins and Phthalocyanines, vol. 5, no. 2, pp. 105-129, 2001.

[11] H. Ali and J. E. van Lier, "Metal complexes as photo- and radiosensitizers," Chemical Reviews, vol. 99, no. 9, pp. 23792450, 1999.

[12] R. Bonnett, "Photosensitizers of the porphyrin and phthalocyanine series for photodynamic therapy," Chemical Society Reviews, vol. 24, no. 1, pp. 19-33, 1995.

[13] A. C. Tedesco, J. C. G. Rotta, and C. N. Lunardi, "Synthesis, photophysical and photochemical aspects of phthalocyanines for photodynamic therapy," Current Organic Chemistry, vol. 7, no. 2, pp. 187-196, 2003.

[14] M. Durmuş, H. Yaman, C. Göl, V. Ahsen, and T. Nyokong, "Water-soluble quaternized mercaptopyridine-substituted zinc-phthalocyanines: synthesis, photophysical, photochemical and bovine serum albumin binding properties," Dyes and Pigments, vol. 91, no. 2, pp. 153-163, 2011.

[15] A. Segalla, C. D. Borsarelli, S. E. Braslavsky et al., "Photophysical, photochemical and antibacterial photosensitizing properties of a novel octacationic $\mathrm{Zn}(\mathrm{II})$-phthalocyanine," Photochemical and Photobiological Sciences, vol. 1, no. 9, pp. 641$648,2002$.

[16] W. Liu, T. J. Jensen, F. R. Fronczek, R. P. Hammer, K. M. Smith, and M. G. H. Vicente, "Synthesis and cellular studies of nonaggregated water-soluble phthalocyanines," Journal of Medicinal Chemistry, vol. 48, no. 4, pp. 1033-1041, 2005.

[17] C. Göl and M. Durmuş, "Investigation of photophysical, photochemical and bovine serum albumin binding properties of novel water-soluble zwitterionic zinc phthalocyanine complexes," Synthetic Metals, vol. 162, no. 7-8, pp. 605-613, 2012. 
[18] B. Ertem, A. Bilgin, Y. Gök, and H. Kantekin, “The synthesis and characterization of novel metal-free and metallophthalocyanines bearing eight 16-membered macrocycles," Dyes and Pigments, vol. 77, no. 3, pp. 537-544, 2008.

[19] A. Bilgin and Y. Gök, "Synthesis and characterization of new metal-free and metallophthalocyanines containing macrobicyclic moieties," Journal of Supramolecular Chemistry, vol. 18, no. 6, pp. 491-499, 2006.

[20] A. Erdoğmuş and T. Nyokong, "New soluble methylendioxyphenoxy-substituted zinc phthalocyanine derivatives: synthesis, photophysical and photochemical studies," Polyhedron, vol. 28, no. 14, pp. 2855-2862, 2009.

[21] G. Gumrukcu, G. K. Karaoglan, A. Erdoğmuş, A. Göl, and U. Avciata, "A novel phthalocyanine conjugated with four salicylideneimino complexes: photophysics and fluorescence quenching studies," Dyes and Pigments, vol. 95, no. 2, pp. 280289, 2012.

[22] G. K. Karaoglan, G. Gumrukcu, A. Koca, and A. Göl, “The synthesis, characterization, electrochemical and spectroelectrochemical properties of a novel, cationic, water-soluble $\mathrm{Zn}$ phthalocyanine with extended conjugation," Dyes and Pigments, vol. 88, no. 3, pp. 247-256, 2011.

[23] G. K. Karaoglan, G. Gumrukcu, A. Koca, A. Göl, and U. Avciata, "Synthesis and characterization of novel soluble phthalocyanines with fused conjugated unsaturated groups," Dyes and Pigments, vol. 90, no. 1, pp. 11-20, 2011.

[24] D. D. Perrin and W. L. F. Armarego, Purification of Laboratory Chemicals, Pegamon Press, Oxford, UK, 2nd edition, 1989.

[25] I. Gürol, M. Durmuş, V. Ahsen, and T. Nyokong, "Synthesis, photophysical and photochemical properties of substituted zinc phthalocyanines," Dalton Transactions, no. 34, pp. 3782-3791, 2007.

[26] Y. Zorlu, F. Dumoulin, M. Durmuş, and V. Ahsen, "Comparative studies of photophysical and photochemical properties of solketal substituted platinum(II) and zinc(II) phthalocyanine sets," Tetrahedron, vol. 66, no. 17, pp. 3248-3258, 2010.

[27] E. T. Saka, M. Durmuş, and H. Kantekin, "Solvent and central metal effects on the photophysical and photochemical properties of 4-benzyloxybenzoxy substituted phthalocyanines," Journal of Organometallic Chemistry, vol. 696, pp. 913-924, 2011.

[28] A. Ogunsipe, J.-Y. Chen, and T. Nyokong, "Photophysical and photochemical studies of zinc(II) phthalocyanine derivativeseffects of substituents and solvents," New Journal of Chemistry, vol. 28, no. 7, pp. 822-827, 2004.

[29] S. Fery-Forgues and D. Lavabre, "Are fluorescence quantum yields so tricky to measure? A demonstration using familiar stationery products," Journal of Chemical Education, vol. 76, no. 9, pp. 1260-1264, 1999.

[30] M. D. Maree, T. Nyokong, K. Suhling, and D. Phillips, "Effects of axial ligands on the photophysical properties of silicon octaphenoxyphthalocyanine," Journal of Porphyrins and Phthalocyanines, vol. 6, no. 6, pp. 373-376, 2002.

[31] J. Rose, Advanced Physico-Chemical Experiments, Pitman, London, UK, 1964.

[32] A. Ogunsipe and T. Nyokong, "Photophysical and photochemical studies of sulphonated non-transition metal phthalocyanines in aqueous and non-aqueous media," Journal of Photochemistry and Photobiology A, vol. 173, no. 2, pp. 211-220, 2005.

[33] J. H. Brannon and D. Madge, "Picosecond laser photophysics. Group 3A phthalocyanines," Journal of the American Chemical Society, vol. 102, no. 1, pp. 62-65, 1980.
[34] I. Seotsanyana-Mokhosi, N. Kuznetsova, and T. Nyokong, "Photochemical studies of tetra-2,3-pyridinoporphyrazines," Journal of Photochemistry and Photobiology A, vol. 140, no. 3, pp. 215222, 2001.

[35] N. A. Kuznetsova, N. S. Gretsova, E. A. Kalmykova et al., "Relationship between the photochemical properties and structure of pophyrins and related compounds," Russian Journal of General Chemistry, vol. 70, no. 1, pp. 133-140, 2000.

[36] W. Spiller, H. Kliesch, D. Wöhrle, S. Hackbarth, B. Röder, and G. Schnurpfeil, "Singlet oxygen quantum yields of different photosensitizers in polar solvents and micellar solutions," Journal of Porphyrins and Phthalocyanines, vol. 2, no. 2, pp. 145-158, 1998.

[37] M. Ozer, A. Altındal, A. R. Ozkaya, M. Bulut, B. Salih, and Ö. Bekâroğlu, "Synthesis, characterization and some properties of novel bis(pentafluorophenyl)methoxyl substituted metal free and metallophthalocyanines," Polyhedron, vol. 25, no. 18, pp. 3593-3602, 2006.

[38] M. Kandaz, M. N. U. Yarasır, A. Koca, and Ö. Bekâroğlu, "Synthesis, characterization and electrochemistry of novel differently octasubstituted phthalocyanines," Polyhedron, vol. 21, no. 3, pp. 255-263, 2002.

[39] V. Ahsen, E. Yilmazer, M. Ertas, and Ö. Bekâroǧlu, "Synthesis and characterization of metal-free and metal derivatives of a novel soluble crown-ether-containing phthalocyanine," Journal of the Chemical Society, Dalton Transactions, no. 2, pp. 401-406, 1988.

[40] I. Özçesmeci, O. Güney, A. I. Okur, and A. Gül, "New phthalocyanines containing bulky electron rich substituents," Journal of Porphyrins and Phthalocyanines, vol. 13, no. 6, pp. 753-759, 2009.

[41] H. Enkelkamp and R. J. M. Nolte, "Molecular materials based on crown ether functionalized phthalocyanines," Journal of Porphyrins and Phthalocyanines, vol. 4, no. 5, pp. 454-459, 2000.

[42] A. Erdoğmuş and T. Nyokong, "Synthesis of zinc phthalocyanine derivatives with improved photophysicochemical properties in aqueous media," Journal of Molecular Structure, vol. 97, no. 1-3, pp. 26-38, 2010.

[43] M. Durmuş and T. Nyokong, "Photophysicochemical and fluorescence quenching studies of benzyloxyphenoxy-substituted zinc phthalocyanines," Spectrochimica Acta A, vol. 69, no. 4, pp. 1170-1117, 2008.

[44] L. Kaestner, M. Cesson, K. Kassab et al., "Zinc octa-nalkyl phthalocyanines in photodynamic therapy: photophysical properties, accumulation and apoptosis in cell cultures, studies in erythrocytes and topical application to Balb/c mice skin," Photochemical and Photobiological Sciences, vol. 2, no. 6, pp. 660-667, 2003.

[45] T. Nyokong, "Effects of substituents on the photochemical and photophysical properties of main group metal phthalocyanines," Coordination Chemistry Reviews, vol. 251, no. 13-14, pp. 1707-1722, 2007.

[46] G. Yasa, A. Erdoğmuş, A. L. Ugur, M. K. Sener, U. Avciata, and T. Nyokong, "Photophysical and photochemical properties of novel phthalocyanines bearing non-peripherally substituted mercaptoquinoline moiety," Journal of Porphyrins and Phthalocyanines, vol. 16, no. 7, pp. 845-854, 2012.

[47] A. Erdoğmuş and T. Nyokong, "Synthesis, photophysical and photochemical properties of novel soluble tetra[4-(thiophen3yl)-phenoxy]phthalocyaninato zinc(II) and $\mathrm{Ti}(\mathrm{IV}) \mathrm{O}$ complexes," Inorganica Chimica Acta, vol. 362, no. 14, pp. 4875-4883, 2009. 
[48] A. Ogunsipe and T. Nyokong, "Effects of central metal on the photophysical and photochemical properties of non-transition metal sulfophthalocyanine," Journal of Porphyrins and Phthalocyanines, vol. 9, no. 2, pp. 121-129, 2005.

[49] J. R. Darwent, I. McCubbin, and D. Phillips, "Excited singlet and triplet state electron-transfer reactions of aluminium(III) sulphonated phthalocyanine," Journal of the Chemical Society, Faraday Transactions 2, vol. 78, no. 2, pp. 347-357, 1982.

[50] M. Idowu and T. Nyokong, "Photophysicochemical and fluorescence quenching studies of tetra- and octa-carboxy substituted silicon and germanium phthalocyanines," Journal of Photochemistry and Photobiology A, vol. 204, no. 1, pp. 63-68, 2009. 

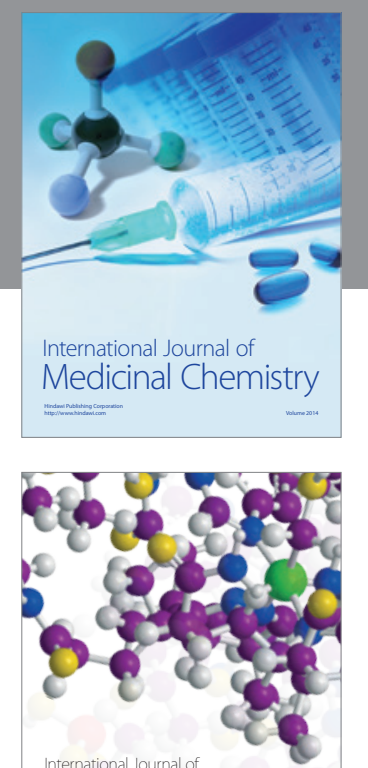

\section{Carbohydrate} Chemistry

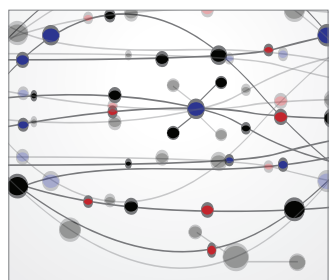

The Scientific World Journal
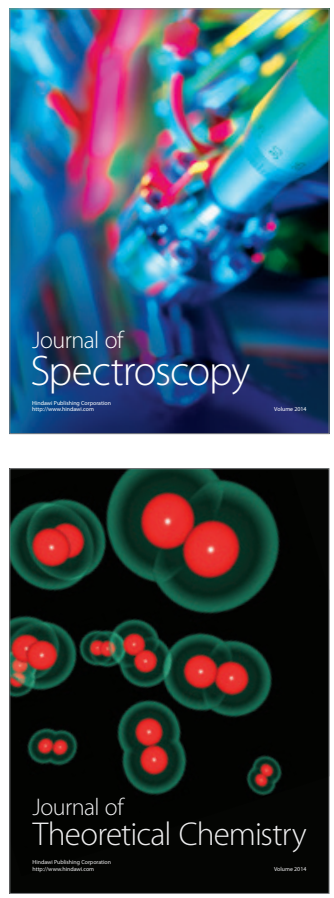
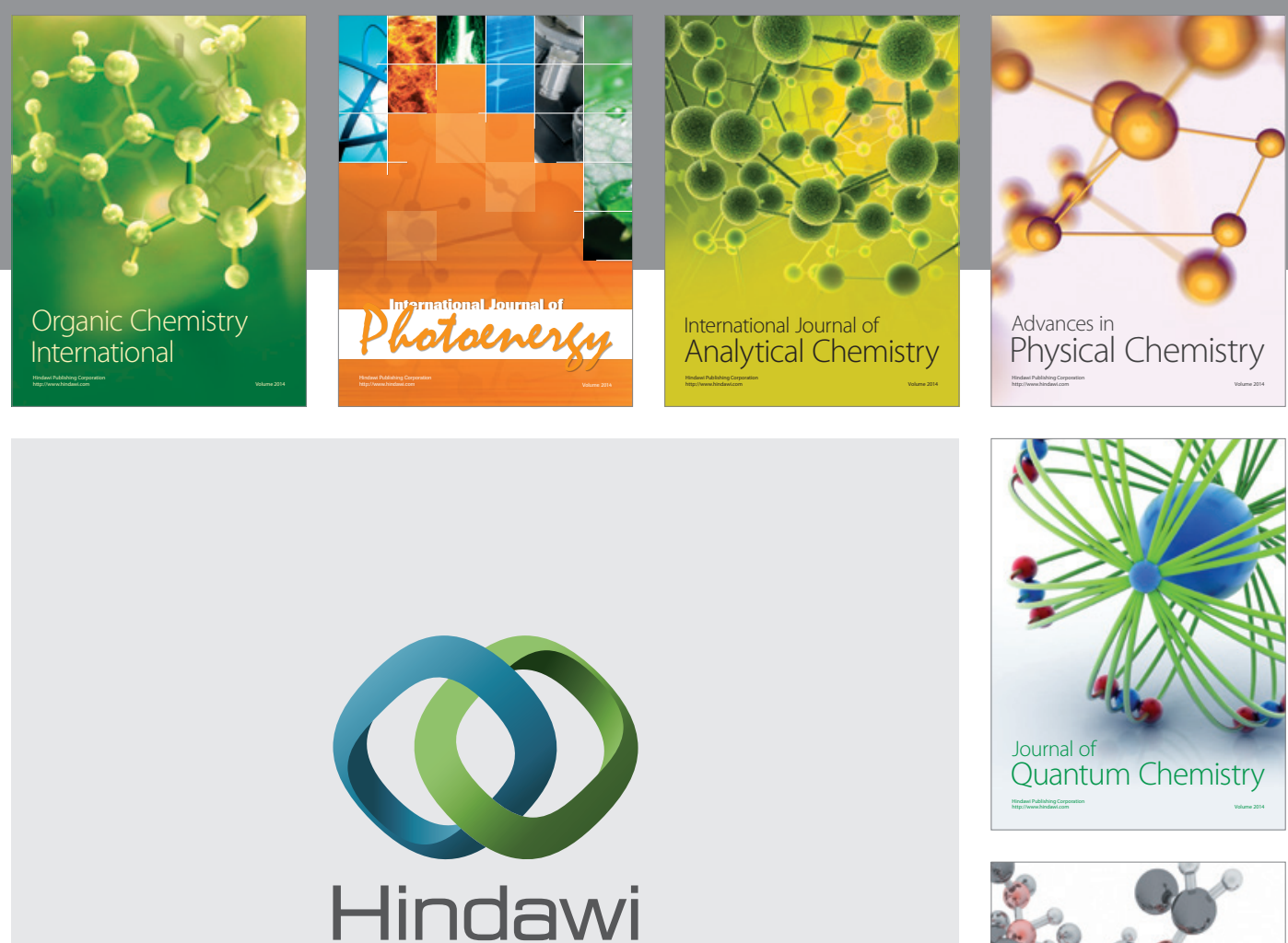

Submit your manuscripts at

http://www.hindawi.com

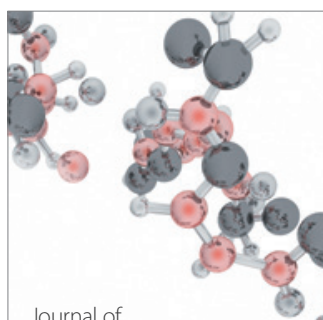

Analytical Methods

in Chemistry

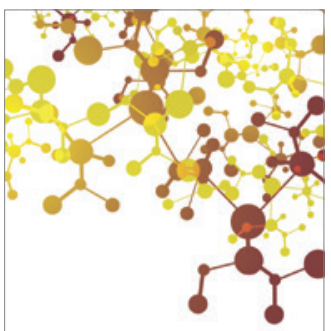

Journal of

Applied Chemistry

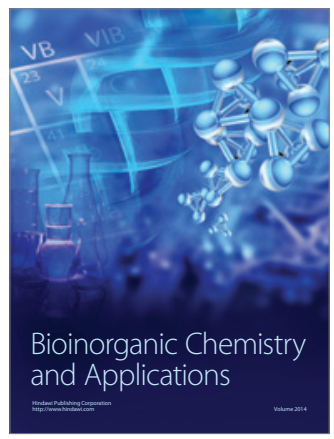

Inorganic Chemistry
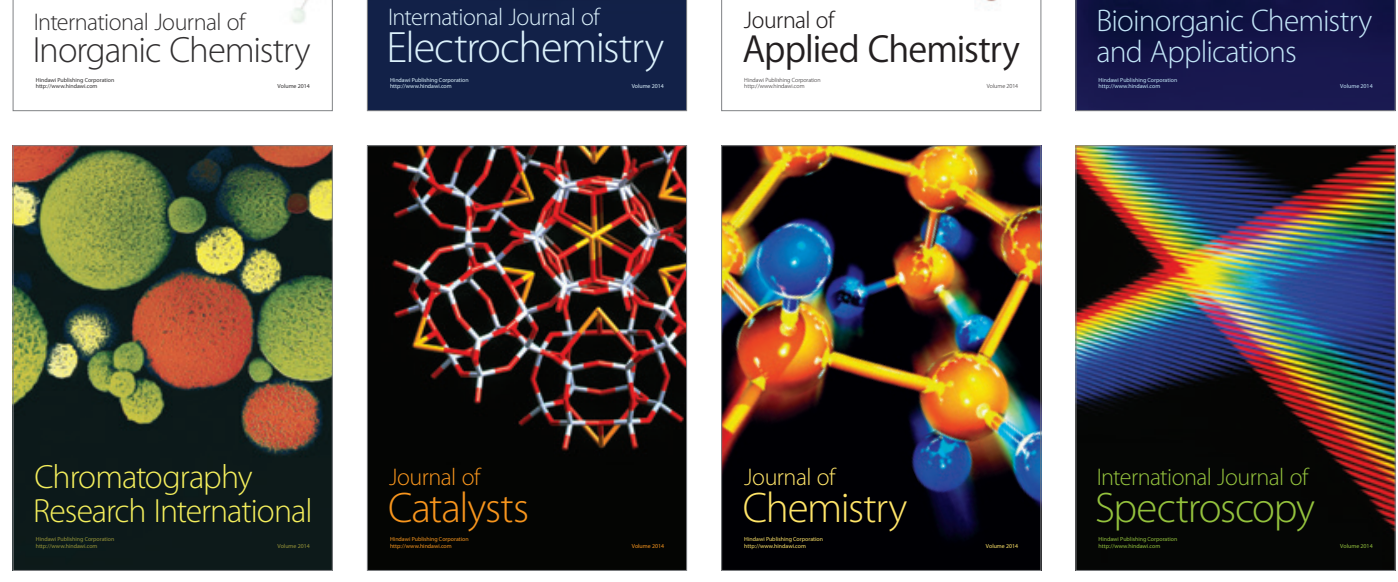